\title{
Chairman Xi Jinping Animated Online Videos: Representation of Paternalistic Leadership in a Postmodern Age
}

\author{
Zhongxuan Dai \\ School of Communication, Hong Kong Baptist University, Hong Kong, China \\ Email:monicadai@life.hkbu.edu.hk
}

How to cite this paper: Dai, Z. X. (2018). Chairman Xi Jinping Animated Online Videos: Representation of Paternalistic Leadership in a Postmodern Age. Chinese Studies, 7, 183-196.

https://doi.org/10.4236/chnstd.2018.72016

Received: February 22, 2018

Accepted: May 27, 2018

Published: May 30, 2018

Copyright $\odot 2018$ by author and Scientific Research Publishing Inc. This work is licensed under the Creative Commons Attribution-NonCommercial International License (CC BY-NC 4.0).

http://creativecommons.org/licenses/by-nc/4.0/

\section{(c) (i) \& Open Access}

\begin{abstract}
Speaking of Chinese Internet, a lot of discussions fall into the "control vs. resistance" paradigm, while beyond such discussions, a possibility is that when people could make use of the Internet, the government could make use of it as well; when certain subversive discourses are welcomed online, certain official ideologies might be welcomed as well. Therefore, under what kind of conditions would official ideologies be welcomed online? Taking the series of $X i$ Dada videos as an example, this article aims to focus on not only its use of western techniques, but also its use of Chinese traditional culture, raising a Zhongtixiyong (Chinese learning as substance, Western learning as function) paradigm. By analyzing the content of Xi Dada animated videos, the article examines how paternalistic leadership with the myth of traditional just officials (qingtian) is embedded in such videos with an adaptation to postmodern culture in Chinese online society.
\end{abstract}

\section{Keywords}

Postmodern Culture, Paternalistic Leadership, Xi Dada Videos, Chinese Internet

\section{Introduction}

Since Chinese chairman Xi Jinping vowed to crack both major power abusers and lowly bureaucrats as "tigers" and "flies" on January $22^{\text {nd }}$ in 2013, the current chairman Xi has "burnished his reputation with Chinese media" as New York Times described. Such a reputation has not only been built among traditional Chinese media but also widely gained online.

One example is that a large number of Chinese Internet users are addressing 
Xi Jinping by a nickname "Xi Dada", which could be translated as Uncle Xi, even Daddy $\mathrm{Xi}$ in certain Chinese dialects. Also, a series of admiring animation videos created for "Xi Dada" are quite welcomed online. The most popular video of this series How are the leaders tempered has got 3,905,694 views together with its English version. The two studios created such videos have been analyzed to be with possible government background (Sohu.com, 2013). Relevant videos and images are reposted by most websites and weibo accounts of mainstream media, including the websites of typical official mouthpieces such People's Daily and Xinhua News Agency, revealing the government's attitude. Therefore, it is fair to claim that such videos are adopted by Chinese propaganda systems as part of its official ideological persuasion, if not created by them directly.

Speaking of Chinese Internet, a lot of discussions fall into the "control vs. resistance" paradigm, about how the government tends to control and filter information, how the Internet is in its nature a medium not easy to be fully controlled, therefore how people could use the Internet to resist official ideology, creating terms like "Grass mud horse" or "River crab", etc. However, despite of such discussions, a possibility which might be neglected is that when people could make use of the Internet, the government could make use of it as well; when certain subversive discourses are welcomed online, certain official ideologies might be welcomed as well. Similar to tabloids, online videos do not have to necessarily "encourage reflection on the social and political structure" (Sparks, 1992: p. 41).

Therefore, under what kind of conditions would official ideologies be welcomed online? The popular "Xi Dada" online videos have provided a chance to partially answer the question. When previous studies have already laid focus on CCP making use of western-style management techniques (Zhao, 2008), this article aims to focus on not only its use of western techniques, but also its use of Chinese traditional culture, raising a Zhongtixiyong (Chinese learning as substance, Western learning as function) paradigm. By analyzing the content of $\mathrm{Xi}$ Dada animated videos, this article examines how paternalistic leadership (Farh \& Cheng, 2000) with the myth of traditional just officials (qingtian) is embedded in such videos with an adaptation to postmodern culture in Chinese online society.

\section{Paternalistic Leadership in China}

When it comes to leadership research, Western leadership styles generally attract more academic attention than Eastern leadership styles. However, simply applying Western leadership theories to the Chinese context might not be suitable enough, as Chinese societies are deeply affected by Confucian values thus with its leadership style possibly built in a different way. Therefore, to study leadership style particularly in Chinese context, some indigenous leadership theories have been developed by Chinese scholars, among which paternalistic leadership theory is one of the most popular. 


\subsection{Paternalistic Leadership and the Revival of Confucianism in China}

Proposed by Farh and Cheng (2000), paternalistic leadership theory is deeply rooted in the country's culture. Borrowing concepts from Confucianism, a three-dimensional scale has been established by Cheng et al. (2000) to further elaborate this leadership style-granting favors (shi'en), inspiring awe or fear (liwei), and setting moral examples (shude), which could be generated into three subtypes accordingly: benevolent, authoritarian and moral leadership. This scale was later proved to be validwith internal consistency (Chen \& Kao 2009; Cheng et al., 2004; Farh \& Cheng 2000).

According to Xiao and $\mathrm{Wu}$ (2014), benevolent leadership is demonstrated by behaviors that "grant favors" such as "individualized care" and "understanding and forgiving", when authoritarian leadership entailed five types of behaviors to "inspire awe or fear": "powerfully subduing," "authority and control," "intention hiding," "rigor," and "doctrine." As for moral leadership, behaviors to "set a moral example" are contained, such as "integrity and fulfilling one's obligations," "never taking advantage of others," and "selfless paragon".

Though deeply rooted in history, paternalistic leadership together with Confucianism is far from outdated in current China. To clear ideological obstacles for economic reform, Deng Xiaoping once initiated a campaign to make people rethink about Maoism which unexpectedly led to people's "belief crises" in official ideologies, even their confidence and faith in the party (Chen, 1995). To deal with such a crisis in its legitimacy and regain mass support (Zhao, 1998), CCP has on one hand used China's high-speed economy to divert people's attention from the ideological vacuum (Yu, 2008), on the other hand, it has used nationalism as another ideological tool, attracting comprehensive social support and rebuilt its legitimacy to govern (Seo, 2005). Despite of its former attitude during cultural revolution, CCP has promoted Confucianism as an important part of Chinese culture since 1990s, absorbing it into state-led nationalism education (Makeham, 2008) as a component of its political ideology (Wu 2014). To serve such a purpose, CCP has reduced Confucianism to its own expression of policies and viewed it instrumentally (Zhao, 1998). Such an attitude has not been changed by $\mathrm{Xi}$, therefore, making use of cultural products representing Confucianism or its related cultural concepts such as paternalistic leadership is not an abrupt act for CCP.

\subsection{Myth of Just Officials (qingtian) under Paternalistic Leadership}

Under typical paternalistic leadership, subordinates tend to be dependent on their leaders, focusing on following their orders and decisions instead of solving problems on their own (Xiao \& Wu, 2014). The leader is expected to act like a parent to his/her followers, bearing their interests and welfare in mind and taking care of them. Thus, the subordinates would be obedient and show gratitude 
in return.

A typical manifestation of such an interaction is that county magistrate is also called parental official (fumu guan) in ancient China. Certain parental officials who can demonstrate uprightness would even be deified and become legendary figures. For example, Bao Zheng, an official during Song Dynasty, gained the honorific title "Judge Bao who brightens the sky" (Bao qingtian) due to his patience to hear people's grievances and his ability to deal with corruption. He dared to punish powerful families when they were found guilty, even impeaching the then emperor's relatives.

After the deification of Bao Zheng, qingtian (judge who brightens the sky) has become a myth in Chinese literature. Upright and just officials are often called qingtian, such as Hai Rui and Yuan Keli in Ming Dynasty. Such a myth is still popular and used in modern Chinese media productions, such as the news stories about Communist official Jiao Yulu or a more recent main melody TV drama Ren Changxia. Although not called as qingtian directly due to CCP's seemingly break from feudalism, despite of media's evolving dressing-up skills, the same myth of traditional just officials could still be identified.

Drawing on these constellations of qualities of the mythic just officials (qingtian) under paternalistic leadership, I will concentrate on the following three aspects in my analysis: official as favor granter (caring and understanding people), awe/fear inspirer (powerfully subduing when dealing with corrupted officials; rigorous with principles) and moral role model (selfless with collective values; fulfilling social obligations).

\section{Effect of a Postmodern Age}

Discussing a certain issue with its context not only includes considering the particular space for it to happen, but also the particular time. According to Green and Roberts (2012), postmodernism has become a major factor on presidential elections in $21^{\text {st }}$ century due to demographic changes. Although there're not any direct presidential elections in China, the country is not immune from such a global trend.

It is necessary to distinguish the concepts of postmodern and postmodernism however, as the former indicates an epoch while the latter indicates not only a cultural and political situation, but also a form of economy (Belak \& Dvorski, 2015). According to Lyotard et al. (1993), a postmodern era is an epoch in which rich societies gradually develop into the post-industrial with a mark of the disappearance of the request for the legitimation of order by society members.

\subsection{Postmodern Culture for Chinese Online Society}

Generally, in the whole developed world (Inglehart, 2000), younger generations are found to hold more postmodern and post-materialist values. They are more "diverse, gender neutral, technology savvy, and confident in their abilities" as Green and Roberts (2012: p. 15) claimed. Although China is not yet a developed 
country, connected more and more closely to the outside world after its open-up policies, it's almost impossible for this country to remain absolutely unaffected by such a global climate, especially for its online society. On one hand, Chinese online society is controlled relatively loosely compared to the off-line world. On the other hand, the majority of Chinese Internet users are generally quite young comparing to the whole population. By December 2015, 75.1\% of Chinese Internet users are aged between 10 to 39 (CNNIC, 2016), which means most of them are raised or born after China's open-up policies thus would be more affected by global culture than former generations. Also, it is possible for the Internet to naturally favor postmodern culture according to De Mul:

"if we can call the computer an ontological machine, it is because it is a machine that deconstructs and reconfigures the spatial and temporal organization of almost anything it encounters.” (De Mul, 2010: p. 33)

Therefore, for above reasons, it is reasonable to view Chinese online society as a context affected by postmodern culture.

\subsection{Postmodern Effect on Leadership}

According to Green and Roberts (2012), politicians clinging to traditional communication skills might have problems to connect with postmodernists successfully, as the heart of traditional institutions would be challenged by certain postmodern traits such as "challenging authority, attacking conventional wisdom, tolerating ambiguity, accepting diversity, and building constructive reality" (p. 15). To illustrate this point, they have raised Barack Obama's campaign as an example of transformational leadership making necessary adaptations to postmodern culture in order to win young voters' hearts.

During a postmodern age, value exchange alone could no longer lay a solid foundation for leadership, on the contrary, personal ability of the leader and his/her influence on beliefs, values, behaviors and actions of others are more important (Belak \& Dvorski, 2015). To further elaborate this point, Schmidt (2006) has raised the characteristics that a postmodern leader should have: adaptable, spiritual-focus, tolerance for ambiguity in life, entrepreneurial in his approach, service-oriented, accountable for action, life-long learners, upgrading performance, and participatory. Therefore, it could be summed up that in order to be effective in a postmodern context, traditional leadership styles (such as transformational leadership) should not sell themselves directly, but should make some adaptations with certain new traits to fit in.

\subsection{Myth of Just Officials (qingtian) Adapting to Postmodern Culture}

Similar to Barack Obama's campaigns, "Xi Dada" animated videos have also managed to sell the chairman's leadership with an adaptation to postmodern culture. This might sound new and westernized, however, adopting such videos as part of official propaganda is actually not an abrupt behavior for CCP, as cer- 
tain clues could be examined from its previous policies.

As Zhao (2008) once proposed, when CCP on one hand intended to continue its Leninist propaganda structure rejuvenating its typical propaganda systems, it had been trying to adopt some Western-style management techniques including the art of public relations and image making in the post-1989 era. Such techniques, "imported from the Western and first adopted by businesses, is now serving the party's propaganda objectives", which contributed to a more "sophisticated propaganda". She has further elaborated this point with examples such as $\mathrm{Hu}$ Jintao making dumplings celebrating Chinese Spring Festival in a rural household. To some degree, the new government is continuing this path by reporting Xi Jinping queueing up with common people to buy steamed bun. Adopting "Xi Dada" animated videos is just another demonstration of such a policy.

As paternalistic leadership has a deep root in Confucianism when postmodernists tend to challenge conventional wisdom instead of embracing it, the traditional myth of just officials (qingtian) must be delicately reconstructed in a postmodern way to make it sell. Combining the previous analysis of the mythic just officials via three aspects with such an adaptation to postmodern traits, a mechanism could be generated as follow:

In the following part, this mechanism as shown in Table 1 would be used to analyze "Xi Dada" animated videos in order to demonstrate how the myth is embedded.

\section{Selling an Old Myth with New Paradigm: Xi Dada Animated Online Videos}

The most popular videos of Xi Dada are produced by two studios: "On the Fuxing Road Studio" and "Beijing Chaoyang Studio".

"On the Fuxing Road Studio" published its first video How are the leaders tempered on October $14^{\text {th }} 2013$ with both versions in Chinese and another in English, using animation to vividly explain the difficulty of becoming a president in China. After more than a year, this studio has uploaded 7 videos as a "Follow Xi Dada" series in 2015: Follow Xi Dada: the Boao Forum on March 24 $4^{\text {th }}$, Bandung Conference and Before the visit to Pakistan both on April, Follow Xi Dada: to Russia on May $4^{\text {th }}$, To America on September $18^{\text {th }}$, To Britain on October $16^{\text {th }}$

Table 1. Just Official Myth and Postmodern Traits, data from (Xiao \& Wu, 2014; Cheng et al., 2000).

\begin{tabular}{|c|c|c|}
\hline Dimensions of the myth & Behaviors & Resonate with postmodern traits \\
\hline Official as favor granter & Caring and understanding people & $\begin{array}{c}\text { Tolerating ambiguity; accepting } \\
\text { diversity; participatory }\end{array}$ \\
\hline Awe/fear inspirer & $\begin{array}{l}\text { Powerfully subduing when dealing } \\
\text { with corrupted officials; rigorous } \\
\text { with principles }\end{array}$ & $\begin{array}{l}\text { Challenging authority; personal } \\
\text { ability of the leader; } \\
\text { spiritual-focus }\end{array}$ \\
\hline Moral role model & $\begin{array}{l}\text { Selfless with collective values; } \\
\text { fulfilling social obligations }\end{array}$ & Accountable for action \\
\hline
\end{tabular}


and To Africa on December $2^{\text {nd }}$. Videos in this series are mostly presented in an unanimated way with interviews of common people, but besides this series, another two animated videos have also been uploaded: Song of the 13th Five-year Plan with both Chinese and English versions on October $26^{\text {th }} 2015$ and True Kung-fu of Chinese economy on April $13^{\text {th }} 2016$.

"Beijing Chaoyang Studio" has also uploaded "Xi Dada" videos with political content. Its first video was uploaded on Jul 2014, which is called Help you see through the tricks of badmouthing China in 5 minutes. Although gained a lot of attention, this video was not what made Beijing Chaoyang Studio's name. During February $17^{\text {th }}, 2015$, at the beginning of Chinese Spring Festival, Beijing Chaoyang studio uploaded three videos in a row: Is the mass line for real, Are the officials really scared and Are civilians' affairs getting handled more easily. This time the videos are also presented in animation, but not just about China as a country in general, instead, the popular term "Xi Dada" and Chairman Xi Jinping's anti-corruption policies are mentioned frequently inside, using his images and words as symbols of the power to intimidate corrupted officials.

Among all these videos mentioning "Xi Dada" or his policies, this article would mainly focus on those animated ones directly using "Xi Dada" as a main character and analyze them with the mechanism mentioned above.

\section{1. "Xi Dada" as a Favor Granter}

As mentioned above, granting favor (shi'en) is one of the three aspects contributing to the construction of just official (qingtian) myth, demonstrating the benevolent aspect of paternalistic leadership, which is mainly about how the official should care about people, truly understanding their grievances and needs.

To demonstrate this point, from the perspective of the videos' content, in the animated video called Are civilians' affairs getting handled more easily, two particular cases are mentioned: a young man working in Beijing has to return to his hometown for 6 times, travelling totally $3000 \mathrm{~km}$ to get his passport prepared; a young married woman has to get documents stamped from different departments for 6 times, collecting 16 certificates to get a pregnancy permit (zhunshengzheng). These are both real cases which have been reported by traditional media and gained public attention. The first one was reported by CCTV about how Mr. Zhou was troubled by officials in Heibei Province when he wanted to get a passport. The latter one was reported by a local newspaper in Guangzhou province, pointing out how hard it was for Ms. Zhou to get a permit for her second child according to the redundant procedures required by provincial government. And then the narrator of this video comes to a conclusion "without money or connections, it would be hard to get things done", which has spoken the minds of many people, demonstrating that the problems are perceived and understood instead of avoided or neglected by the narrator and the power-bloc he's representing. 
Neglecting problems and hardships encountered by people and setting public focus on the positive sides of certain great works to ease public tensions is one of the traditional strategies adopted by some Chinese leaders and the media system under their leadership. However, to gain popularity, contradictions could actually be exploited instead of avoided:"Unlike official news, popular news makes no attempt to smooth out contradictions in its discourse: indeed it exploits them, for unresolved contradictions are central to popular culture" (Fiske, 1992: p. 52).

By exposing existing contradictions, leaders could gain a chance to pose themselves as problem-solvers and favor granters, protecting people from troubles and villains, which are just how the image of Xi Jinping has been represented in the following content of this video: "now the activity of mass-line education and implement is coming along. The scalpel is raised, focusing on the 'difficult labor' in bureaucracy to get documents done". Although the narrator doesn't mention "Xi Dada" directly, his image has been used here, cutting a sign named with "difficult labor to get documents done" with a scalpel together with another person.

From the perspective of visual semiotics, as a contrast, when corrupted officials acting as villains in this video are represented with exaggerated arrogant attitudes towards civilians, Xi's image is agreeable and friendly, even with the usage of his video clips to add a sense of reality and humanity.

Comparing Figure 1 and Figure 2, for the corrupted official, people are keeled unwillingly with grimaces when the official is standing alone, which has enlarged the different heights of their images. Also, people kneeling around the officials are all young males, a group who are usually perceived as more powerful than children, seniors or females. Therefore, the fact of making such a comparatively powerful group to kneel has exaggerated the power-distance between the leader and subordinates to an extreme, which has vividly contrasted the image of $\mathrm{Xi}$ as the people surrounding him are seated or half-seated, providing an appropriate height difference. Also, they are mostly female seniors, a group usually

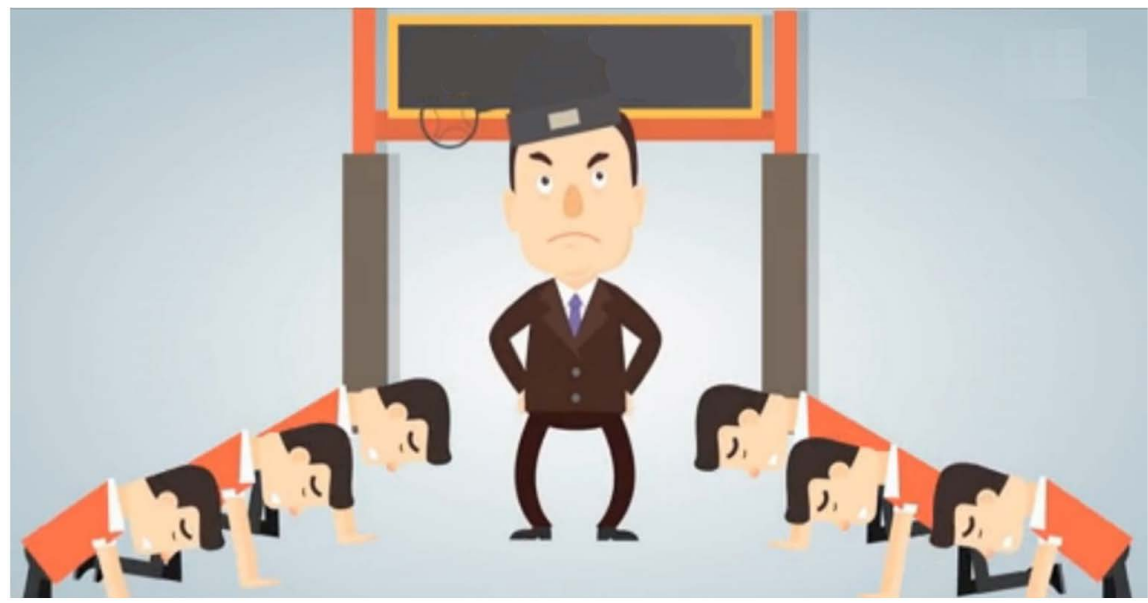

Figure 1. Power Distance-Corrupted official. 


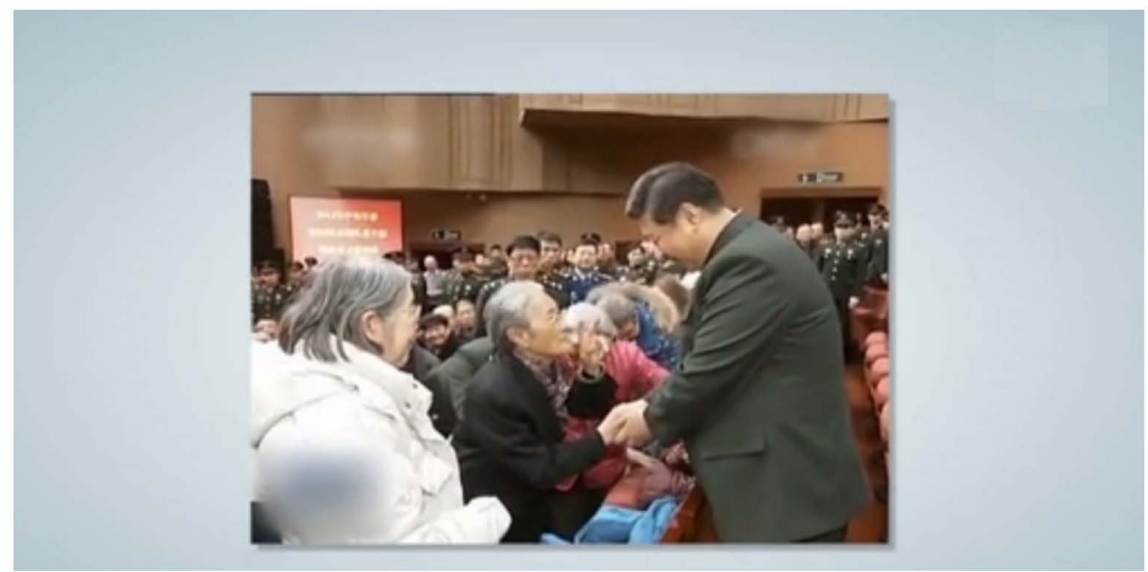

Figure 2. Power Distance-Chairman Xi.

considered as comparatively weak and requiring care. Therefore, the appropriate power-distance demonstrated in this image is exactly enough for Xi to take up the role as a caring male leader granting his favors to senior ladies with face-to-face communication.

Besides demonstrating the granting-favor aspect in its traditional way, certain postmodern traits for leaders are also resonated in these videos such as tolerating ambiguity, accepting diversity and participatory.

A good example of how the trait of participatory is represented is an image of $\mathrm{Xi}$ having meals together with people in Lankao County in the video is the mass line for real. As the narrator mentioned, "after Xi Dada arrived Lankao, he ate home-made meals and spoke considerate words (with people)".

In Figure 3, $\mathrm{Xi}$ is portrayed as standing in the middle surrounded by people, with two of them wearing white head scarfs marking their role as peasants. The foods on table are typical ordinary food in northern China such as steamed buns and a corn. Also, the words in the dialog box reads as "another bowel (of rice please)" indicating that $\mathrm{Xi}$ is enjoying this ordinary meal with peasants with pleasure instead of any discomfort. These attributes all demonstrate that $\mathrm{Xi}$ is very able and willing to participate in ordinary people's activities.

As for the traits of tolerating ambiguity and accepting diversity, the manifestation of these animated videos could act as a proof. Chinese societies have a tradition of treating people in higher status as taboos to show respect. As a result, when it comes to Chinese government leaders, usually related reports would be serious to show respect, eliminating any trivia or entertaining elements. Actually, in previous news reports, there were "very strict regulations" on the use of political leaders' images, usually such reports would directly use images provided by Xinhua agency. Also, these images were not allowed to be stitched or flipped, in fact, cartoons of political leaders had disappeared from the scene since some cartoons of Deng Xiaoping during the 1980s (Liu \& Song, 2013). Therefore, stitching the image of a leader's head to an animated body would be considered as disrespectable according to previous CCP polices. However, all of these "Xi Dada" animated online videos have used such a way to 


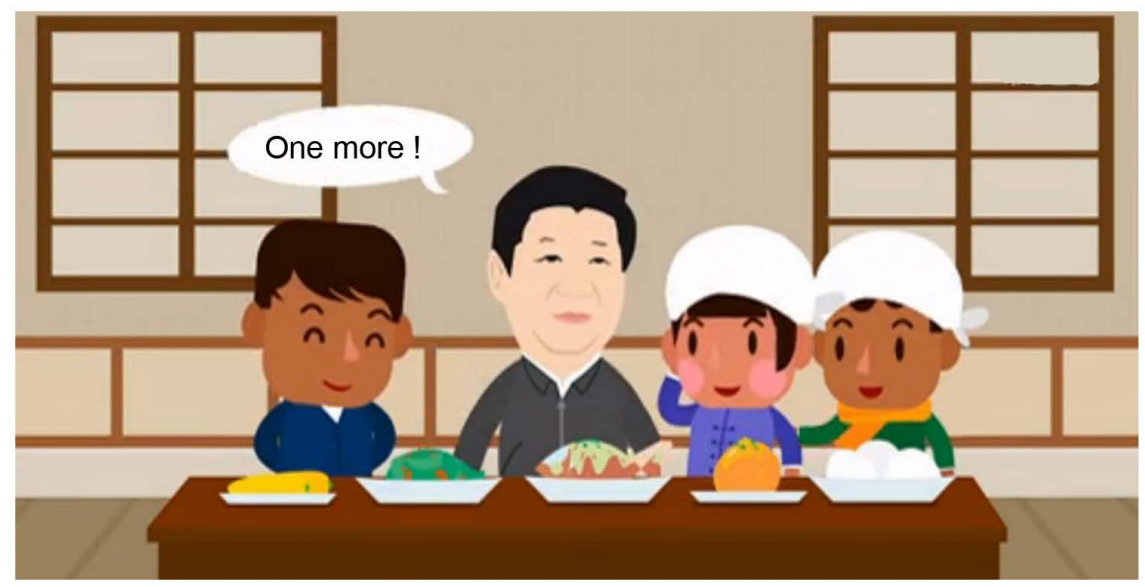

Figure 3. Chairman Xi in Lankao.

represent "Xi Dada", demonstrating more diverse and ambiguous methods when representing his leadership. Also, such videos have been adopted by mainstream media as part of official propaganda with the leader's consent. Such an act itself has also demonstrated his traits of tolerating ambiguity and accepting diversity.

\section{2. "Xi Dada" as an Awe/Fear Inspirer}

Inspiring awe/fear is another aspect of the mythic just officials (qingtian) paralleling with the authoritarian dimension of paternalistic leadership, which could be demonstrated by behaviors such as powerfully subduing when dealing with corrupted officials and rigorous with principles.

For "Xi Dada" videos, those introducing his anti-corruption policies could fall right into the category of "powerfully subduing when dealing with corrupted officials", such as the video is the mass line for real and Are the officials really scared. Statistical evidences are raised by the narrator in both videos to demonstrate the strict implement of such policies: "more than 4000 officials have been investigated due to treating themselves to restaurants with state expenses. More than 100,000 officials have been laid off due to holding their positions without doing work. It seems that the mass line is for real!" "After the implement of mass line for more than a year, CCP has investigated and dealt with more than 3000 officials for creating difficulties for civilians; more than 4000 officials for accepting bribes; more than 6000 officials for abusing their power for personal gain and more than 200,000 officials for damaging civilians' interests."

With all the numbers paralleling together, Xi's anti-corruption policies are portrayed to be carried out vigorously with irresistible power, contributing to the construction of his powerful image, besides raising numbers and facts, such as point has been illustrated via images as well.

Since Xi has vowed to crack both major power abusers and lowly bureaucrats as "tigers" and "flies", the tiger in the video is the mass line for real is a symbol representing "major power abusers". Usually tigers are perceived to be fierce and scary, but in above image, Xi dares to face a tiger alone with a mace, making it 
stare with fright, contributing to Xi's image as a man with a strong hand, who is "powerfully subduing when dealing with corrupted officials".

Another aspect of the awe/fear inspiring dimension is how the leader is portrayed as a person "rigorous with principles", which might be able to resonate with the postmodern trait "spiritual-focus". For "Xi Dada" videos, it's important to think about one question first: Xi could be presented as rigorous with what kind of principles? Focusing on what kind of spirits? Due to CCP's seemingly break with feudalism, representing him as a strong protector of traditional principles too directly would be not very appropriate, therefore, a more acceptable alternative is to reconnect him with traditional CCP principles. The video Is the mass line for real has done this job by mentioning "mass-line policy has been a cherished heirloom since the Yan'an days. However, certain officials are still corrupted today. Xi Dada has noticed this problem right after he took the chair, thus starting a rectification movement in this new age".

With such a narrative, "certain officials" are portrayed as violators of some valuable principles, when $\mathrm{Xi}$ is portrayed as an upright protector. Also, the image when mentioning CCP's Yan'an days resonates with posters during cultural revolution. Both of them use 3 figures to represent people with different professions: a person with white head scarf to represent peasants, a person with cap to represent workers. What might be different is the third figure, when the poster during cultural revolution adopted a figure with military uniform to represent soldiers, the image in Xi Dada videos has replaced it with a figure looks like an educated white-collar worker, reflecting the policy shift from military to economy. Also, the little red books in those people's hands are replaced with a traditional-style book named "mass line". Generally, the resonance could evoke a sense of nostalgia and remind people of certain rigorous principles during old days, implicating that $\mathrm{Xi}$ is rigorous with traditional CCP principles.

When portraying the authoritarian aspect of Xi's leadership, certain postmodern traits for leaders are resonated as well, particularly "personal ability", "challenging authority" and "spiritual-focus". When raising statistical evidence to emphasize the effectiveness of Xi's policies, the personal ability of Xi is generally highlighted at the same time. Also, the fact of many corrupted officials being dealt with and the image of Xi facing "tiger" with a mace have demonstrated Xi's courage to challenge authority (though he is in fact also part of it), making people feel like they've finally find a leader who dare to do them justice and help them to take their anger out. For "spiritual-focus", on one hand, when corrupted officials are portrayed with taking material benefits, as a contrast, the image of $\mathrm{Xi}$ would be more spiritual-focus as a result. On the other hand, by emphasizing how Xi's rigorous with traditional CCP principles and recalling people's memories of CCP's old days, Xi's spiritual-focus aspect has been highlighted as well, because during the old days, the party used to encourage people, especially party members, to make the most use of their spiritual power and value the material return to the least. 


\section{3. "Xi Dada" as a Role Model}

Paralleling with the moral dimension of paternalistic leadership, acting as moral examples is also an aspect to construct the myth of just official (qingtian), which contains aspects such as "selfless with collective values" and "fulfilling social obligations", resonating with postmodern trait "accountable for action" for leaders. The video How are the leaders tempered has vividly portrayed a strong-minded image of Xi by demonstrating how he has been fulfilling his social obligations during the process of becoming the chairman of China. As the narrator mentioned, "in China, officials are ranked with a hierarchy. Typically, one starts at the primary level, and then is promoted successfully to township/section, county/division, department/bureau and province/ministry levels. Among China's 7 million officials, only one out of every 140,000 makes this far and it takes more than 20 years. Take Xi jinping, president of China, as an example, he experienced 16 major job transfers and governed an accumulative population of over 150 million over 40 plus years...In this system, before a party member could take of the helm of Chins, he would have sailed through all kinds of rapids and shoals."

By mentioning "one out of 140,000 officials", "16 job transfers", "40 plus years" and "all kinds of rapids and shoals", this video is trying to emphasize the pressure and difficulties during the process of becoming Chinese chairman. By describing the difficulties, $\mathrm{Xi}$ as the final winner who has made it would naturally gain an image of "accountable for action", also willing and capable to "fulfill social obligations", otherwise he would not have survived such hardships.

As for the "selfless with collective values" aspect, the whole video of Is the mass line for real reflect collective values, setting selfish corrupted officials as a contrast to Xi. Also, this video has especially mentioned Xi's visit in Lankao County, which is a symbol of "selflessness with collective values" since the county is where the official Jiao Yulu served as the secretary of the county Party committee. As mentioned above, the myth of just official (qingtian) could be identified in most news reports about Jiao Yulu, who was reported to be devoting himself tirelessly to work, even diagnosed with liver cancer and died during work eventually. After his death, a campaign was started in 1966 setting him as a moral example to encourage people, especially party members, to be more selfless and devoted to work. Therefore, by mentioning Xi's visit to Lankaoin particular and how he has enjoyed meals with local peasants, would make a connection between Xi's image and Jiao's, thus contributing to the construction of Xi as a selfless moral example.

\section{Conclusion}

By analyzing "Xi Dada" animated online videos, this article has contributed to examining the conditions for official ideology to be welcomed online. On one hand, taking Chinese culture into consideration, this article has identified how Chinese traditional myth of just officials (qingtian), which is a result of paternalistic leadership, has been embedded in these videos via three aspects. On the 
other hand, it has mentioned how certain aspects of this myth in "Xi Dada" videos could resonate with some postmodern traits of leaders, thus adapt to Chinese online culture and gain popularity.

According to above analysis, the hybrid of paternalistic leadership and postmodern traits for leaders in the myth embedded in these videos is what has made this video popular online. Despite of the seemingly break with feudalism or western-style management, in post-1989 era, it could be identified that the party doesn't really mind making use of either traditional Chinese or Western strategies to solidify its dominance. As the previous leader Deng Xiaoping once mentioned: "no matter it's white cat or black cat, those catch mouses are good cats".

Selling a traditional myth with western techniques could be viewed as a political reflection of Zhongtixiyong: "Chinese learning as substance ( $t i)$ and Western learning as function (yong)" (Tu, 1993: p. 164), which was once raised by some Chinese intellectuals such as Yan Fu, Wei Yuan and Liang Qichao. Back at the time, those intellectuals believed that Confucianism as a core for Chinese traditional culture should not be shaken but certain western science and technologies could be adopted to empower this country, thus came to the conclusion of Zhongtixiyong.

This idea might seem to be irrelevant with the party's policies at first glance, however, no matter how different the party seems to be compared with former Chinese governments, it is still an inseparable part of this country historically with its leaders inevitably affected by Chinese culture.

As a result, the fact of Chinese internet users resisting official propaganda online should not be taken for granted, which might just be one aspect of a multifaceted system, since the relationships between people and official systems, between people and the Internet are both complicated. As Fiske once mentioned, "the system that subordinates the people can also sustain and protect them ... it is always in process as the people chart their paths through the social determinations that both constrain and empower them" (Fiske, 1992: p. 52-53). For the "Xi Dada" case, such animated videos could be viewed as a representation of how people are empowered, as the image of leaders is no longer hard and cold but now reconstructed in a way adapting to people's taste to attract them. However, it could also be viewed as a representation of how people are constrained as well, since no matter how the images are reconstructed, a myth favoring the power-blocs has been embedded and welcomed as an eventual result.

\section{References}

Belak, V., \& Dvorski, K. (2015). Old Ideas, New Paradigms: A Postmodern Discourse on Leadership. 867-880.

http://search.proquest.com/docview/1717432517?accountid=11440

Chen, H., \& Kao, H. (2009). Chinese Paternalistic Leadership and Non-Chinese Subordinates' Psychological Health. International Journal of Human Resource Management, 20, 2533-2546. https://doi.org/10.1080/09585190903363839

Chen, J. (1995). The Impact of Reform on the Party and Ideology in China. Journal of 
Contemporary China, 4, 22-34. https://doi.org/10.1080/10670569508724221

Cheng, B., Chou, Li., Wu, T., Huang, M., \& Farh, J. (2004). Paternalistic Leadership and Subordinate Responses: Establishing a Leadership Model in Chinese Organizations. Asian Journal of Social Psychology, 7, 89-117. https://doi.org/10.1111/j.1467-839X.2004.00137.x

CNNIC. (2016). Statistical Report on Internet Development in China. http://www1.cnnic.cn/IDR/

De Mul, J. (2010). Cyberspace Odyssey: Towards a Virtual Ontology and Anthropology. Cambridge Scholars Publishing.

Farh, J., \& Cheng, B. (2000). A Cultural Analysis of Paternalistic Leadership in Chinese Organizations. In A. S. Tsui, \& J. T. Li (Eds.), Management and Organizations in the Chinese Context (pp. 84-127). London: Macmillan.

Fiske, J. (1992). Popularity and the Politics of Information. In P. Dahlgren, \& C. Sparks (Eds.), Journalism and Popular Culture (pp. 45-63). Newbury Park, Calif; London: SAGE Publications.

Green, D. D., \& Roberts, G. E. (2012). Transformational Leadership in a Postmodern World: Presidential Election of Barack Obama. Academy of Strategic Management Journal, 11, 9-25.

Inglehart, R. (2000). Globalization and Postmodern Values. The Washington Quarterly, 23, 215-228. https://doi.org/10.1162/016366000560665

Lyotard, J., Harvey, R., \& Roberts, M. (1993). Toward the Postmodern (Philosophy and Literary Theory). Atlantic Highlands, NJ: Humanities Press International.

Makeham, J. (2008). Lost Soul: “Confucianism” in Contemporary Chinese Academic Discourse. Cambridge, MA: Harvard University Asian Center for the Harvard-Yenching Institute. https://doi.org/10.2307/j.ctt1dnnbvz

Schmidt, H. (2006). Leadership in a Postmodern World. http://www.mbseminary.edu/current/images/article/schmidtl.htm

Seo, J. (2005). Nationalism and the Problem of Political Legitimacy in China. In W. Lynn (Ed.), Legitimacy: Ambiguities of Political Success or Failure in East and Southeast Asia (pp. 141-182). Singapore: World Scientific. https://doi.org/10.1142/9789812569349_0005

Sohu.com (2013). Who Made the Videos of Leaders? http://business.sohu.com/s2013/jrzj228/

Sparks, C. (1992). Popular Journalism. In P. Dahlgren, \& C. Sparks (Eds.), Journalism and Popular Culture (pp. 24-44). Newbury Park, CA, London: SAGE Publications.

Tu, W. (1993). Way, Learning, and Politics: Essays on the Confucian Intellectual. Albany: SUNY Press.

Xiao, M., \& Wu, X. (2014). Chinese Leadership: Culture and Confucianism. Public Integrity, 16, 165-172. https://doi.org/10.2753/PIN1099-9922160204

Yu, T. (2008). The Revival of Confucianism in Chinese Schools: A Historical-Political Review. Asia Pacific Journal of Education, 28, 113-129. https://doi.org/10.1080/02188790802036653

Zhao, S. (1998). A State-Led Nationalism: The Patriotic Education Campaign in Post-Tiananmen China. Communist and Post-Communist Studies, 31, 287-302. https://doi.org/10.1016/S0967-067X(98)00009-9

Zhao, Y. (2008). Communication in China: Political Economy, Power, and Conflict. Lanham, MD: Rowman \& Littlefield. 